\title{
CHARACTER OF ZHALMAUYZ IN THE FOLKLORE OF TURKIC PEOPLES
}

\author{
Pakizat Auyesbayeva ${ }^{1}$, Akbota Akhmetbekova ${ }^{2}$, Zhumashay Rakysh ${ }^{3 *}$ \\ ${ }^{1} \mathrm{PhD}$ in of philological sciences, M. O. Auezov Institute of Literature and Art, Kazakhstan, \\ ksaryarka@inbox.ru \\ ${ }^{2} \mathrm{PhD}$ in of philological sciences, Al-Farabi Kazakh National University, Kazakhstan, \\ axbota@mail.ru \\ ${ }^{3} \mathrm{PhD}$ in of philological sciences, M. O. Auezov Institute of Literature and Art, Kazakhstan, \\ zhumashay1970@gmail.com \\ ${ }^{*}$ Corresponding author
}

\begin{abstract}
Among the Turkic peoples Zhalmauyz Kempir character, compared to other demonological characters, is widely used in genres. The transformation of this character from seven-headed villain - Zhalmauyz kempir to mystan kempir was seen. This very transformation is associated with the transition of society from matriarchy to patriarchy. Zhalmauyz is a syncretic person. She acts in the character of an evil old woman. This character is the main image of the evil inclination in the Kazakh mythology. She robs babies and eats them, floating on the water surface in the form of lungs, cleeks everybody who approached to the river and strangle until she will agree to give up her baby. In some tales she captures the young girls and sucks their blood through a finger deceiving or intimidating them. Two mythical characters in this fairy-tale image - mystan Kempir and ugly villain - Zhalmauyz are closely intertwined. In the Turkic peoples Zhalmauyz generally acts as fairy-tale character. But as a specific demonological force Zhalmauyz refers to the character of hikaya genre. Because even though people do not believe in the seven-headed image of this character, but they believes that she eats people, harmful, she can pass from the human realm into the demons' world and she is a connoisseur of all the features of both worlds. Zhalmauyz is a mythical image, which is as chthonic ghosts, destroys all flesh. Zhalmauyz is representative of the underworld, which is struggling with the world of light, she tends to extinguish the torch of life, draw the disaster and destroy all flesh. Zhalmauyz function, aimed at the destruction of life by absorbing the sun, the moon and the reign of darkness, surely connects her with the nether world. Based on her act of the sun and the moon absorbing, you can imagine her as bottomless, pitch substance with a huge mouth. There is not a portrait of Zhalmauyz in fairy tales, we get information in the course of its destruction only by destroying her one eye or cutting off her seven heads, and only through these acts we know that she was one-eyed, or seven-headed. Finally, we can say that the image of Zhalmauyz Kempir in Kazakh folklore was influenced by different historical periods - from the image of mythical ghosts in ancient times, and then in the form of a shapeless body, and later in the image of seven-headed villain, and in the process of the matriarchy collapse she appeared in the image of Zhalmauyz Kempir.
\end{abstract}

Keywords: folklore, mythology, hikaya, genre. 


\section{INTRODUCTION}

Among the Turkic peoples Zhalmauyz kempir character, compared to other demonological characters, is widely used in genres: myths, fairy-tales, hikaya, heroic poems, legends.

The character, called by Kazakh and Kara-Kalpak people as "Zhalmauyz Kempir", by Kirhgiz people "zhalmoaz, zhalmoguz kempir", by Karachai and Balkar people - "dzhelmauuz", by Chuvash people "yelmeves", by Uigur people - "yalmauz", by Uzbek people - "yalmogiz (kampir), zhalmovir", by Nogay people - "yelmauyz", by Tatars - "zhalmavyz, zhalmavyz karchyk", by Bashkirs - "ubyrly karsyk, meskey". A. Toishanuly claims that the character "zhalmauyz" is called by Tuva people "chylbygy-moos", and by Khakas people - "chilbigen" (Toishanuly, 2009, p.105).

G.N. Potanin sustaines the idea, that the word "zhalmauyz" derives from two words: "zhalmau" (meaning in Turkic language "devour") and "mangus" or "mogus" ("a monster"), whereas Ye.D. Tursynov thinks that this nomination is the result of word-composition of the two Kazakh words - "zhamlau" and "auyz" ("mouth"), meaning "the mouth, devouring everything". The meaning of the word "devour, consume" is revealed with the help of the equivalent in semantics words as "meshkey" and "opyrly", i.e. "opyrushy" (meaning "the one who digs out"), "opyryp zheushi" ("the one who devours insatiably").

\section{THEORETICAL BACKGROUND}

The transformation of this character from seven-headed villain - Zhalmauyz kempir to mystan kempir was seen. This very transformation is associated with the transition of society from matriarchy to patriarchy (Konyratbaev, 1987, p.54). S.Kondybaev characterizes Zhalmauyz is a syncretic person: "She acts in the character of an evil old woman. This character is the main image of the evil inclination in the Kazakh mythology. She robs babies and eats them, floating on the water surface in the form of lungs, cleeks everybody who approached to the river and strangle until she will agree to give up her baby. In some tales she captures the young girls and sucks their blood through a finger deceiving or intimidating them. Two mythical characters in this fairy-tale image - mystan kempir and ugly villain - Zhalmauyz are closely intertwined". (Kondybaev,1999,p.22). The characteristics of Zhalmauyz that are very similar to these features are mentioned in the encyclopedia (The Myths of Peoples of the World, 1987, p.439). S.A. Kaskabasov described the image of Zhalmauyz in detail from the point of view of fairy-tales characters (Kaskabasov, 1972). R. Almukhanova in her work "The Ancient Motives in Kazakh Folklore" makes the survey of the investigations of Sh. Valikhanov, M.Auezov, G.N. Potanin, A.Konyratbayev, S.A. Kaskabasov, V.Ya. Propp and while describing "Zhalmauyz kempir" and poiting out its functional similarity to the acient mythical images, concludes the following: "Finally, we can say that the image of Zhalmauyz kempir in Kazakh folklore was influenced by different historical periods - from the image of mythical ghosts in ancient times, and then in the form of a shapeless body, and later in the image of seven-headed villain, and in the process of the matriarchy collapse she appeared in the image of Zhalmauyz Kempir" (Almukhanova, 2006,p.163).

\section{METHODOLOGY}

In the material we use the historical and comparative methods. And we compare the character "Zhalmauyz Kempir" with other Turkic folklore.

The study investigated Kazakh-speaking students of higher educational institutions of Almaty city. The study was conducted at Al-Farabi National University, Institute of Literature and Art named after M. Auezov.

\section{RESULTS}

In the Turkic peoples Zhalmauyz generally acts as fairy-tale character. But as a specific demonological force Zhalmauyz refers to the character of hikaya genre. Because even though people do not believe in the sevenheaded image of this character, but they believes that she eats people, harmful, she can pass from the human realm into the demons' world and she is a connoisseur of all the features of both worlds. "Zhalmauyz kempir" has a mythical origin. The transfer of this character from a "mythical" to the character of the "hikaya" genre consists of three stages:

1) Transformation from teratological monster to the seven-headed cannibal - Zhalmauyz;

2) From seven-headed Zhalmauyz - to "Zhalmauyz Kempir";

3) From "Zhalmauyz Kempir" - to "mystan" (crone-witch).

On the first stage the function of this monster was limited to devouring only ("zhalmau") and served as the explanation of such natural phenomena as sun and moon eclipse. 
Zhalmauyz is a mythical image, which is as chthonic ghosts, destroys all flesh. Tuva people and Mongols have the myths that link up both sun and moon eclipses with the fact, that Zhalmauyz swallows these celestial bodies. Zhalmauyz is representative of the underworld, which is struggling with the world of light, she tends to extinguish the torch of life, draw the disaster and destroy all flesh. Zhalmauyz function, aimed at the destruction of life by absorbing the sun, the moon and the reign of darkness, surely connects her with the nether world. These «mythical traces» of the character Zhalmauyz can be found in "Dutan-batyr" (a Tatar fairy-tale), in Kazakh fairy-tales "Totan batyr", "Kun astyndagy Kunekei kyz" and other fairy-tales, in Zhalmauyz's errands to the heroes (bogatyr) to kidnap and bring the girl Kunike, i.e. the Sun (Kun).

Based on her act of the sun and the moon absorbing, you can imagine her as bottomless, pitch substance with a huge mouth. There is not a portrait of Zhalmauyz in fairy tales, we get information in the course of its destruction only by destroying her one eye or cutting off her seven heads, and only through these acts we know that she was one-eyed, or seven-headed.

As the continuation of the myths, in which Zhalmauyz reaves away the symbol of life - the Sun and the symbol of beauty - the Moon, in the "hikaya" genre Zhalmauyz is depicted as the character, who sucks the blood from young girls' fingers and reaves beauty from them, leaving them half-dead.

And when myths began to lose their relevance, Zhalmauyz splits into two characters: seven-headed tazhal (all-devouring monster), referred to ssubterraneous world and "Zhalmauyz Kempir" (all-devouring crone), and in the fairy-tales she acts as a character, controls by Tazhal. This mission of hers can be observed in such her actions as mending the hole in the earth and guarding the fissure, leading to the subterraneous world. We can also notice that later her function is restricted to being the guard of the way to the subterraneous world. In many hikayas Zhalmauyz as a guard of the way to the world of the dead, lives in the isolated deserts or on the edge of the woods, i.e. inhabits the borderline between the territories, where people settle, and the territory, which is dangerous for people.

In the myths, where the aetiology of the Sun and the Moon eclipses or of their everyday rises and sets, the acts of the revival of celestial bodies and their resurrection can be observed. It is especially concerned with it, because the responsibilities of initiation with making the parallels between the changes, connected with the moon phases, physiological changes and the changes, concerned with the status and rank of a person in society in the tradition of the majority of peoples in the epoch of matriarchy were performed by a woman as a dominant. It seemed that a woman-mother, fulfilling the functions of the head of the tribe or clan, was not only the representative of the clan cult, priestess, but she was also a saint, having rich life experience, a fortune-teller, a healer. The fact, that in many texts she is mentioned as having the functions of the mistress of fire, the giver of fire, proves that she was the head of the hearth (family). As the representative of the cult she performed the initiation - a ritual transfer of a boy to the status of a man, and a girl - into a woman. This function can be found in the fairy-tale "Altyn saka", where "Zhalmauyz Kempir" demands to bring her the boy, and in the fairy-tale Zhalmauyzdy aldagan kyzdar (The girls, who cheated Zhalmauyz), in which Zhalmauyz chases the girls, who ran away from her only by using such purely womanly things as a needle, comb, mirror. But later, when patriarchy substitute for matriarchy, this function acquires negative connotation and the priestess, holy mother transforms into "Zhalmauyz Kempir". Although in the epoch of patriarchy Zhalmauyz Kempir loses her status, authority, but she preserves her activity due to her functions. This activity determines her close interrelation with people and led to the process of transformation of Zhalmauyz Kempir into "mystan" (crone-witch). In the folklore of Turkic people six types of plots, concerning Zhalmauyz Kempir can be found:

1) By widely opening her mouth she swallows people and all their belongings. Here Zhalmauyz acts in her passive position as the character, who is the guard of a particular territory and punishes the disturbers of her territorial property. For the penetration of the main character of the fairy-tale to the forbidden territory she levies a tax on him by giving him errands and demanding to serve her.

2) She gives her daughter the task to boil the girls, who wonder by mistake to her dwelling, chases the girls to revenge the death of her daughter on them. This plot is similar to the story of one-eyed devas (Cyclops).

3) She swims on the water surface looking like lungs and demands from the person she caught to bring his son to her. Her appearance in the form of lungs is concerned with the beginning of syncretization of the characters of Zhalmauyz and Albasty.

4) She sucks the blood out of the finger of a girl, who was left at home alone or without any fire. In this plot Zhalmauyz is connected with the character of a ghoul (upyr'), who can be come across more often in Tatar and Bashkir fairy-tales. 
5) She helps the characters of the fairy-tale, who happen to be in the subterraneous world. It is the emergence in "hikaya" of the image of a mother-priestess, shaman, who fulfills the functions, aimed at preventing seven-headed Tazhal from going out of the world of the dead and taking control of this exit.

6) She performs the evil intents of people: kidnapping of children, lulling the heroes and passing them in sleep in the hands of their enemies, seducing beautiful women. In these plots Zhalmauyz is already deprived of her demonological features and turned to a usual crone-witch (mystan kempir).

\section{CONCLUSION}

All in all specific features of the character of Zhalmauyz Kempir are connected with the fact of its origin as a merging of the image of a mythical monster and the image of a mother-priestess, who either serves this monster or fights with it. It means that Zhalmauyz Kempir is the character that has been formed as a result of inter-transfer of functions - one into another - of the god and the priestess, serving this god. In the course of the transfer of the mythical character in the hikaya the monster loses its teratological image and acquires a human one. The monstrosity of this character is revealed primarily not with the ugly appearance of the crone with "hoofed head and nose-beak", but mainly by means of her harmful deeds and evil intents. In the fairytales of the Tatars and the Bashkir, who live close to the Russians, Zhalmauyz Kempir resembles such characters of Russian fairy-tales as "hag" ("ved'ma"), "ghoul" ("upyr") more. And Turkic peoples, living close to the Mongols, describe the mythical image of this character as zhelbege (chilbigen). In the fairy-tales of nomadic Turks her physical strength is emphasized more, due to which Zhalmauyz can oppose to batyrs or even defeat them in the image of mystan kempir (crone-witch) with the help of her craftiness.

\section{REFERENCE LIST}

Almukhanova R.Antique motives in the Kazakh folklore. Almaty: Arys, 2009. 320 p.

Kaskabasov S.A. Zhanazyq. Astana: Audarma, 2002. 584 p./ Kazakh fairy-tale. Alma-Ata, Nauka, 1972. $258 p$.

Kondybayev S. Introduction into the Kazakh mythology. Almaty: Zerde, 1999. 304 p.

Konyratbayev A. Kazakh epos and Turkology. Almaty: Nauka, 1987. 368 p.

The Myths of Peoples of the World. V.1 .M., 1987. 671p.

Toishanuly A.Turco - Mongolian Mythology: Monographya.Almaty: Dom Izdatelstvo, 2009. 192 p. 